\title{
Super large cardiac hemangioma in right atrium and inferior vena cava: case report
}

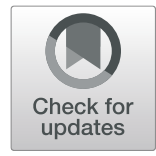

\author{
C. J. Perez Rivera* (D, R. Figueroa-Casanova(D, C. E. Ochoa Bonet(1) and A. González-Orozco (D)
}

\begin{abstract}
Background: Cardiac hemangiomas are rare cardiac neoplasia usually diagnosed in autopsies, from being asymptomatic to debuting with sudden death. The largest hemangioma published in the literature is of $130 \mathrm{~mm}$ size, we present the following case of a successful cardiac hemangioma excision of $280 \times 35 \mathrm{~mm}$ in size, diagnosed due to recurrent cardiac symptoms.

Case presentation: A 48-year-old female patient, Jehovah's Witness, with no previous diagnoses, is admitted due to recurrent syncopal episodes in the previous months. A transthoracic echocardiogram diagnosed a tumor in the right atrium and inferior vena cava producing a diastolic right ventricular, with preservation of the left ventricular ejection fraction at 55\%. Given the high mortality risk, a surgical intervention was performed immediately. Successful excision was completed confirming a $280 \times 35 \mathrm{~mm}$ mass without any complications, consistent with hemangioma on histopathology. Postoperative recovery showed no recurrence or complications.

Conclusions: Cardiac hemangiomas are rare and its clinical course can be varied from patient to patient. We present excision of a large cardiac mass with a high mortality risk due to its size and the patient's spiritual beliefs.
\end{abstract}

Keywords: Cardiac hemangioma, Right ventricular prolapse, Jehovah's witness, Case report

\section{Background}

The first cardiac hemangioma case report was published by Uskoff in 1893 [1]. Although cardiac neoplasia are rare $(0.28 \%)$, most are diagnosed in autopsies, with hemangiomas being only $5 \%$ of these cases [2]. Histologically, hemangiomas are classified in the principal categories: cavernous, capillary, and arteriovenous [3]. The physiopathology varies from patient to patient, some being completely asymptomatic while others debuting with sudden death. Miao and colleagues published a revision of 67 cases of cardiac hemangiomas with an average size of $52.3 \mathrm{~mm}$, the largest being $130 \mathrm{~mm}$, which to this day is the largest reported. We present the following case report of a successful $280 \mathrm{~mm} \times 35 \mathrm{~mm}$ hemangioma excision that produced a right ventricular diastolic prolapse, proving a high mortality risk of the patient.

\section{Case presentation}

A 48-year-old female patient, with spiritual beliefs of Jehovah's Witness, arrives into the emergency department

\footnotetext{
* Correspondence: cjperezrivera@gmail.com

Department of Cardiovascular Surgery, Medical Doctor, Clinica Avidanti, Av. 19 \#10 315, Ibagué, Tolima, Colombia
}

due to multiple syncopal episodes the months prior, without any neurological deficits. A transthoracic echocardiogram was performed showing dilatation of the inferior vena cava and a $<50 \%$ collapse of an echogenic and heterogeneous image arising $13 \mathrm{~cm}$ from the right atrial opening occupying large part of it and producing a diastolic right ventricular prolapse (Fig. 1). This was a mobile longitudinal mass extending into the right chambers, despite this the left ventricular ejection fraction was preserved at $55 \%$. Given the patient's high complications risk due to embolism or sudden death, a surgical intervention was performed immediately.

The surgery was performed with an on-pump beatingheart cardiopulmonary bypass $(\mathrm{CPB})$ without aortic crossclamping or cardioplegic arrest. A direct superior intravenous access into the superior vena cava was achieved as well as a peripheral femoral vein access with multipurpose of active drainage \#25. The right atrium was accessed via a longitudinal incision parallel to the atria-ventricular groove. The cavity was explored confirming the $280 \times 35$ $\mathrm{mm}$ (length $\mathrm{x}$ width) mass that extended from the inferior vena cava to the right atrium. Excision was successfully performed without any complications (Fig. 2), the cavity 


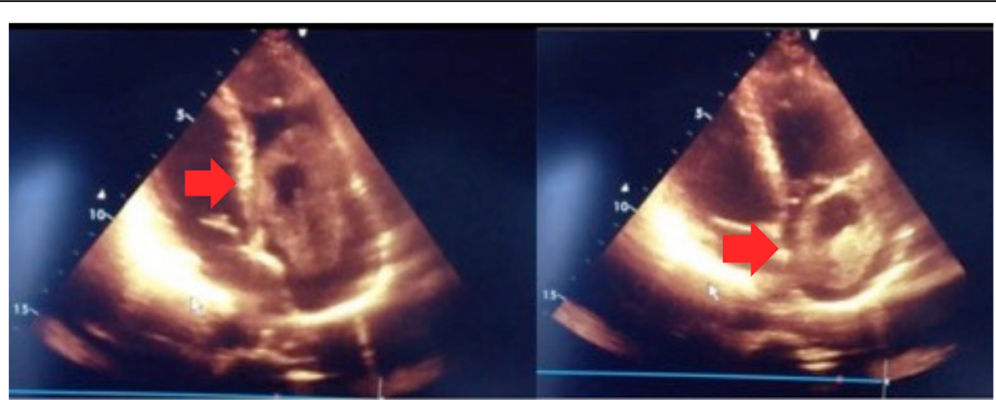

Fig. 1 Transthoracic echocardiogram. Longitudinal view of the transthoracic echocardiogram showing a diastolic prolapse into the right ventricle (red arrows)

was then explored with no evidence of thrombus or additional masses.

The patient had a successful postoperative recovery, a postoperative transthoracic echocardiogram was performed without evidence of any recidivating masses. The patient endured a 5-day in-hospital care and was discharged without any complications. The histologic report confirmed a hemangioma of arteriovenous type. Patient follow-up 3, 6, and 12-months later reported a SF-36 of $95 \%$ (minimal disability).

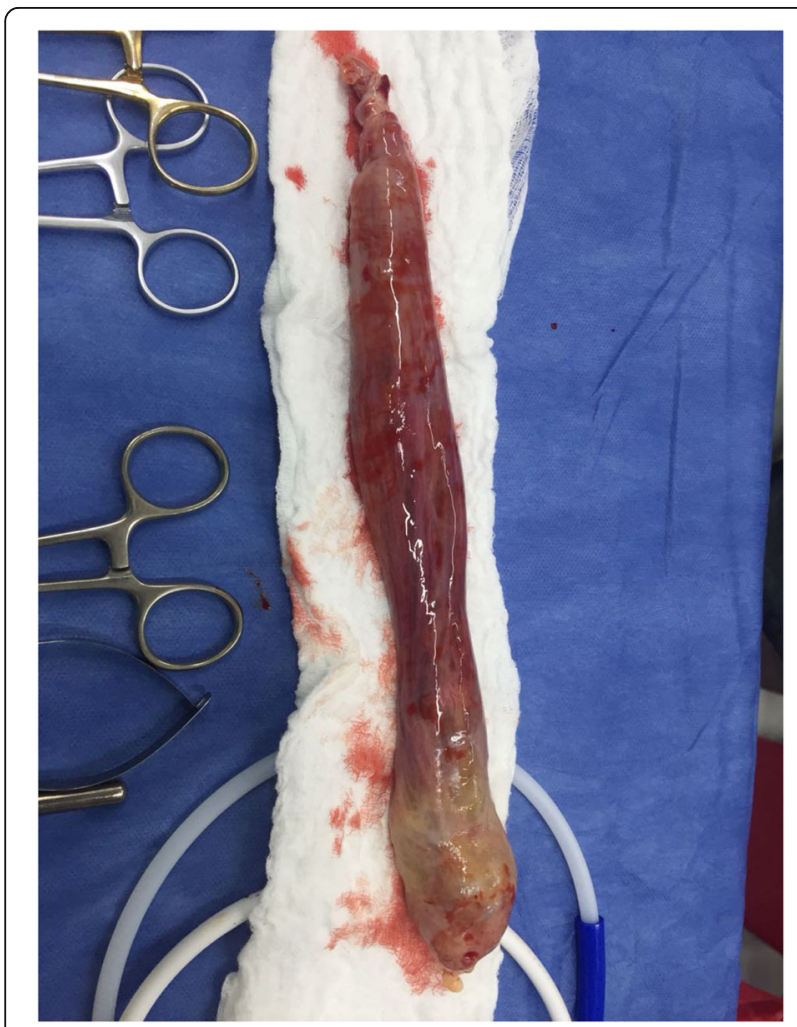

Fig. 2 Intraoperative hemangioma. Intraoperative specimen removed, $28 \mathrm{~cm} \times 3.5 \mathrm{~cm}$ (length $\mathrm{x}$ width) mass

\section{Discussion}

Cardiac hemangiomas are rare primary cardiac tumors, with an incidence of only $1-2 \%$ of all cardiac primary tumors. These tumors are classified based on their histologic appearance in three categories: cavernous, capillary, and arteriovenous. The cavernous type has small vessels in its border with multiple dilations, the capillary type has numerous small-vessels similar to capillaries, while the arteriovenous has dysplasia of the arteries and veins [3]. This histological difference arises from hyperplasia or abnormal dilation of the small arterioles, venules, and capillaries [4]. They can appear at any stage of life and cardiac chamber, however they are most commonly found in the atrium. Although the clinical manifestations are varied, depending on the age of the patient, chamber localization, size, and rate of growth, most symptomatic patients have hemodynamic repercussions from valve, coronary vessels, or electrical pathways changes. Complex cases can involve other organs due to extrinsic compression, such as esophageal, tracheal, or ventricular prolapse like in this case report, resulting in high embolization risk.

Complementary images are of diagnostic use only, given that the definite diagnosis is histopathologic. However, an echocardiogram, computed tomography (CT) scan, CT angiography, or cardiac magnetic resonance image (MRI) will provide precise details that can be used in the operative approach. Given our patient's clinical presentation and the high embolic or sudden death mortality risk, an immediate surgical excision was required. As of 2018, reports of Jehovah's Witness supporters are estimated to be approximately 8 million worldwide, which as is common knowledge can be difficult to treat due to their beliefs in cardiac interventions [5]. However, in this case report a successful excision was completed without cardiac arrest with an on-pump beating-heart to minimize risks, achieving an excellent result with no reported complications short or long-term.

Previous reports of right chamber hemangiomas have recently been reported, however most have been of 
significant small sizes. Jiang et al. reported an excision of a right ventricular $68 \times 50 \times 26 \mathrm{~mm}$ mass without any hemodynamic repercussion [6]. Additionally Iida et al. also reported a $28.2 \times 22.8$ mass located in the right ventricle surface [7], as did Samanidis et al. with a $51 \times 52 \times$ $88 \mathrm{~mm}$ mass located in the right atrium without extension to any other chambers [8]. Lastly, Takahashi et al. did report a larger than usual hemangioma $(60 \times 60 \mathrm{~mm})$ located in the left atrial appendage [9]. The importance of this case report reveals the compromise compared to other large hemangiomas, given that in our case report the mass affected the right chambers of the heart due its large size and subsequently proved a high-risk situation for the patient.

\section{Conclusions}

The incidence of cardiac hemangioma is low and its clinical course can be varied from patient to patient. We have described a unique case of a Jehovah's Witness patient as well as a challenging and difficult surgical case. The key to proper management is a multidisciplinary approach as well as expertise and proper communication between physicians.

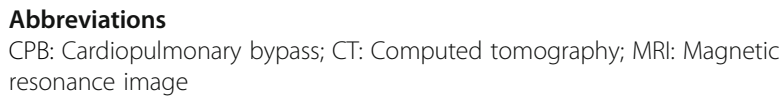

\section{Acknowledgements}

None.

\section{Authors' contributions}

PR-CJ, OB-CE and GO-A designed the report, analyzed the data, and wrote the paper. FC-R collected patient's data and was the perioperative attending physician. All authors read and approved the final manuscript.

\section{Funding}

No funding was provided for this report.

\section{Availability of data and materials}

The dataset supporting the conclusions of this article is included within the article

\section{Ethics approval and consent to participate}

the Ethical and Research Committee of the Avidanti Clinic.

\section{Consent for publication}

Written consent was obtained from the patient for publication of this report. Any details identifying the individuals to the clinical history and images associated were eliminated as to remain anonymous.

\section{Competing interests}

The authors declare that they have no competing interests.

Received: 16 September 2019 Accepted: 28 October 2019

Published online: 05 November 2019

\section{References}

1. Sulayman R, Cassels DE. Myocardial coronary hemangiomatous tumors in children. Chest. 1975;68(1):113-5.

2. Beebeejaun MY, Deshpande R. Conservative management of cardiac haemangioma. Interact Cardiovasc Thorac Surg. 2011;12(3):517-9.

3. Zhao H, Tao T, Davies H, Lu Y, Xu H. Right atrium hemangioma in patient with history of mixed thrombus surgery. J Card Surg. 2019;34(5):356-8.
4. Miao H, Yang W, Zhou M, Zhu Q, Jiang Z. Atrial hemangioma: a case report and review of the literature. Ann Thorac Cardiovasc Surg. 2019;25(2):71-81.

5. Bernal JM, Naranjo S, Trugeda M, Sarralde A, Diago C, Revuelta JM. Cirugía cardiaca en testigos de Jehová. Experiencia en Santander. Rev Esp Cardiol. 2006;59(5):507-9.

6. Jiang WJ, Li JH, Dai J, Lai YQ. Cardiac hemangioma at the apex of the right ventricle: a case report and literature review. J Thorac Cardiovasc Surg. 2014;147(3):e18-21.

7. lida Y, Ito T, Kitahara H, Takebe M, Nemoto A, Shimokawa R, Yoshitake A, Misumi T. Successful detection and surgical treatment of cardiac Hemangioma with right ventricular invasion. Ann Thorac Surg. 2013;96(4):1481-3.

8. Samanidis G, Khoury M, Balanika M, Dimitrou S, Michalis A. Cardiac cavernous haemangioma: diagnosis and treatment. ANZ J Surg. 2014;84(4):294-5.

9. Takahashi A, Sakurai M, Fujikawa T. Resection of a giant cardiac hemangioma. Gen Thorac Cardiovasc Surg. 2013;61(6):353-5.

\section{Publisher's Note}

Springer Nature remains neutral with regard to jurisdictional claims in published maps and institutional affiliations.
Ready to submit your research? Choose BMC and benefit from:
- fast, convenient online submission
- thorough peer review by experienced researchers in your field
- rapid publication on acceptance
- support for research data, including large and complex data types
- gold Open Access which fosters wider collaboration and increased citations
- maximum visibility for your research: over $100 \mathrm{M}$ website views per year
At BMC, research is always in progress.
Learn more biomedcentral.com/submissions 